\title{
ПРОБЛЕМЫ АДМИНИСТРАТИВНОЙ ОТВЕТСТВЕННОСТИ ЗА ПРОЖИВАНИЕ ГРАЖДАНИНА РОССИЙСКОЙ ФЕДЕРАЦИИ БЕЗ РЕГИСТРАЦИИ ПО МЕСТУ ПРЕБЫВАНИЯ
}

\begin{abstract}
Аннотация. Объектом исследования являются общественные отношения, складывающиеся в сфере регистрационного учета граждан Российской Федерации по месту пребывания и административной ответственности за отсутствие регистрации по месту пребывания в жилом помещении. Предметом исследования являются нормы статьи 19.15.1. Кодекса Российской Федерации об административных правонарушениях, а также положения Конституции РФ и Федерального закона от 25 июня 1993 г. № 5242-1 (ред. от 31.12.2014 2.) «О праве граждан Российской Федерации на свободу передвижения, выбор места пребывания и жительства в пределах Российской Федерации». Руководящим методом исследования является диалектический подход к рассмотрению поставленных проблем в сочетании с критическим отношением к пробелам и несовершенствам законодательства в сфере регистрационного учёта, к административной ответственности за его несоблюдение. Научная новизна исследования заключается в том, что нами предлагается ограничить административную ответственность за проживание без регистрации по месту пребывания в жилом помещении, то есть применять её только к потенциально опасным гражданам РФ. Для законопослушных граждан регистрация по месту пребывания в жилом помещении, как и ответственность за её отсутствие должны быть на законодательном уровне отменены. Обязанность регистрироваться законопослушным гражданам России по месту пребывания создаёт им неудобства в осуществлении конституционного права на свободу передвижения, выбор места пребывания и жительства. Для лии, имеющих судимость за совершение умышленных преступлений, лии, ведущих антиобщественный образ жизни, лии, состоящих на учёте в наркологических и психоневрологических диспансерах и иных социально опасных лиц регистрация по месту пребывания должна быть обязательной.
\end{abstract}

Ключевые слова: регистрация, регистрационный учет, жилое помещение, место пребывания, административное правонарушение, административная ответственность, внутренняя миграция, объект, объективная сторона, субъективная сторона.

Abstract. The research object is the range of social relations in the sphere of residence registration of the citizens of the Russian Federation and administrative liability for the absence of the residence registration in the living accommodation. The research subject covers the provisions of the article 19.15.1 of the Code of Administrative Offences of the Russian Federation, and the provisions of the Constitution of the Russian Federation and the Federal Law of 25 June 1993 № 5242-1 (version of 31 December 2014) "On the right of citizens of the Russian Federation to the freedom of movement and residence within the territory of the Russian Federation". The leading research method is the dialectical approach together with the critical vision of the gaps and the drawbacks of the legislation in the sphere of registration, and the liability for its violation. The author offers to limit administrative liability for residing without a registration, and to impose it only on the potentially dangerous citizens of the Russian Federation. The residence registration and the liability for its absence should be abolished for law-abiding citizens. The necessity to have a residence registration for law-abiding citizens hampers the implementation of the right to the freedom of movement and residence. The residence registration should be obligatory for the citizens having a criminal record for intentional crimes, having asocial way of life, registered in narcological or psychoneurologic dispensaries, or other socially dangerous persons.

Key words: registration, registration, living accomodation, residence, administrative offence, administrative liability, inmigration, object, objective side, subjective side.

$\mathrm{B}$ соответствии с частью 1 статьи 27 Конституции Российской Федерации [2] каждый, кто законно находится на территории Российской Федерации, имеет право свободно передвигаться, выбирать место пребывания и жительства. Это важнейшее конституционное право касается не только граждан Российской Федерации, но и иностранных граждан и лиц без гражданства.
К отношениям внутренней миграции применяется федеральный закон от 25 июня 1993 г. № 5242-1 (ред. от 31.12.2014 г.) «0 праве граждан Российской Федерации на свободу передвижения, выбор места пребывания и жительства в пределах Российской Федерации» [6] (далее по тексту федеральный закон №5242-1), который вводит понятие регистрационного учета как административной обязанности всех граждан России. В случае 


\section{Административное и муниципальное право 4 (100) • 2016}

неисполнения либо ненадлежащего исполнения данной обязанности наступает административная ответственность в соответствии со статьями $19.15^{1}$ и $19.15^{2}$ Кодекса Российской Федерации об административных правонарушениях [1] (далее по тексту КоАП РФ). В отличие от федерального закона № 5242-1, вступившего в силу еще до принятия Конституции Российской Федерации, административная ответственность за правонарушения, предусмотренный вышеуказанными статьями КоАП РФ появилась относительно недавно, а именно введена Федеральным законом от 21.12.2013 г. № 376-Ф3 «0 внесении изменений в отдельные законодательные акты Российской Федерации» [7]. Другими словами в юридическую силу указанные статьи вступили с 2014 года. Ранее действовала статья 19.15 КоАП РФ, которая предусматривала административную ответственность за проживание гражданина Российской Федерации без удостоверения личности гражданина (паспорта) или без регистрации. При этом диспозиция части 1 статьи 19.15 КоАП РФ предусматривала ответственность как за отсутствие регистрации по месту жительства, так и по месту пребывания. На первый взгляд, ранее действующая редакция статьи 19.15 КоАП РФ как бы включала в себя действующую ныне статью $19.15^{1}$ КоАП РФ, а в ныне действующей редакции проживание гражданина без регистрации по месту пребывания или по месту жительства регулируется уже отдельной статьей $19.15^{1}$ КоАП РФ. Вот только наказуемым стало данное деяние за проживание без регистрации в жилом помещении, чего раньше не было в диспозиции статьи 19.15. То есть законодатель ограничил административную наказуемость данного деяния отсутствием регистрации не везде, а именно в жилом помещении, иными словами регистрация по месту пребывания или по месту жительства может осуществляться только в жилом помещении, что вполне, на наш взгляд, разумно.

Проблема нами видится здесь в том, что ряд граждан Российской Федерации не имеют жилого помещения ни на праве собственности, ни на каком-либо ином вещном праве, и эта категория лиц не может подлежать ответственности, так как им найти жилое помещение и зарегистрироваться в нем бывает очень сложно, либо их вполне устраивает проживание в нежилых помещениях. Особенно это касается лиц без определенного места жительства. Подлежат ли они административной ответственности по статье $19.15^{1}$ КоАП РФ? Видимо, нет, поскольку они не проживают в жилом помещении, а живут в подвалах, на чердаках, на помойках, где зарегистрироваться им нельзя. А в соответствии с вышеупомянутой ранее действовавшей редакцией статьи 19.15 КоАП РФ данная категория лиц подлежала административной ответственности, в том числе и за проживание (где угодно, а не только в жилом помещении) без регистрации по месту пребывания.

Исходя из этого, мы видим, что законодатель с одной стороны ужесточил обязанность регистрироваться в жилом помещении под угрозой административной ответственности не только по месту жительства (что вполне разумно), но и по месту пребывания свыше установленного срока. С другой стороны, законодатель же ограничил пределы административной ответственности жилым помещением, исключив лиц, не проживающих в жилых помещениях, из субъектов, подлежащих административной ответственности, за проживание без регистрации по месту пребывания.

Следует также отметить, что ряд законопослушных граждан России имеют на праве собственности либо ином вещном праве земельные участки с дачными домиками, находящимися на территории других субъектов РФ, которые не признаются жилыми помещениями в соответствии с буквой закона. А значит привлечь к ответственности по статье $19.15^{1}$ КоАП РФ за проживание без регистрации по месту пребывания в дачном домике данных лиц нельзя, а таких же граждан, но проживающих в жилых помещениях, закон обязывает регистрироваться по месту пребывания под угрозой административной ответственности. Справедливо ли это? На наш взгляд, конечно же нет.

С давних пор паспортизация населения и регистрационный учет являются формой контроля государства за миграцией граждан в целом, а применительно к гражданам Российской Федерации за процессами внутренней миграции. Статья $19.15^{1}$ КоАП РФ предусматривает административную ответственность за проживание гражданина Российской Федерации по месту пребывания или месту жительства в жилом помещении без регистрации, а статья $19.15^{2}$ КоАП РФ за нарушение правил регистрации гражданина Российской Федерации по месту пребывания или по месту жительства в жилом помещении.

В данной статье мы рассмотрим актуальную, на наш взгляд, проблему административной ответственности за проживание граждан РФ без регистрации по месту пребывания, поскольку, по нашему мнению, существование подобной обязанности для законопослушных граждан России создает им массу проблем и неудобств в реализации конституционного права на свободу передвижения и выбор места пребывания. Для того чтобы понять весь спектр этих проблем, возникающих в связи с новым для современного российского законодательства административным правонарушением, предусмотренным статьей $19.15^{1}$ КоАП РФ, разберем его по 
составу. Как и для преступления, для административного правонарушения характерно наличие следующих элементов состава: объект, объективная сторона, субъект и субъективная сторона.

Объектом всегда являются общественные отношения различных видов, выделяют родовой объект и непосредственный объект. Родовым объектом для данного правонарушения являются общественные отношения, складывающиеся в управленческой деятельности, не зря статья $19.15^{1}$ КоАП РФ входит в главу 19 КоАП РФ, устанавливающую ответственность за административные правонарушения против порядка управления. Непосредственным же объектом указанной статьи являются отношения регистрационного учета, подробно регламентируемые федеральным законом № 5242-1. Данный Закон в статье 2 дает легальное определение регистрационного учета, под которым понимается государственная деятельность по фиксации и обобщению предусмотренных настоящим Законом сведений о регистрации граждан Российской Федерации по месту пребывания, регистрации граждан Российской Федерации по месту жительства, снятии граждан Российской Федерации с регистрационного учета по месту пребывания и снятии граждан Российской Федерации с регистрационного учета по месту жительства в пределах Российской Федерации. Регистрационный учет граждан Российской Федерации имеет уведомительный характер и отражает факты прибытия гражданина Российской Федерации в место пребывания или место жительства, его нахождения в указанном месте и убытия гражданина Российской Федерации из места пребывания или места жительства [6].

Ряд исследователей справедливо отмечают, что «в целях более эффективного осуществления паспортно-регистрационного учета граждан России необходимо совершенствовать его административно-правовое регулирование, имея в виду, прежде всего принятие Федерального закона «0 паспортно-регистрационном учете граждан Российской Федерации в Российской Федерации» по аналогии с ныне действующим правовым регулированием миграционного учета иностранных граждан. Указанный закон включил бы в себя общие принципы правового регулирования, в том числе прописав уведомительный характер регистрации, основные понятия, вопросы изъятия документов, удостоверяющих личность, а также их проверки» [4, с.388].

В соответствии с ныне действующим законодательством наше, казалось бы, свободное в соответствии с Конституцией РФ передвижение и свободный выбор места пребывания подлежит обязательной фиксации в компетентных государственных органах, причем сам гражданин России обязан зарегистрироваться по месту пребывания, если срок его пребывания составляет более 90 дней [6].

Данную обязанность устанавливает федеральный закон № 5242-1 в статье 3, где прямо указано, что граждане Российской Федерации обязаны регистрироваться по месту пребывания и по месту жительства в пределах Российской Федерации. Там же сказано, что регистрационный учет вводится в целях обеспечения необходимых условий для реализации гражданином РФ его прав и свобод, а также исполнения им обязанностей перед другими гражданами, государством и обществом. Иными словами государство как бы оправдывает регистрационную обязанность граждан России необходимостью обеспечить непонятно, какие условия, для реализации неясных нам прав и свобод, которые якобы без данного учета по месту пребывания реализованы быть не могут. Обязанность регистрации по месту пребывания может быть оправдана, на наш взгляд, лишь в случае обязанности регистрации отдельных категорий граждан РФ (лиц, ранее судимых за умышленные преступления, лиц, состоящих на учете в наркологических и психоневрологических диспансерах, лиц, состоящих на учете в детской комнате полиции и иных потенциально опасных для общества граждан). Для законопослушных граждан РФ, зарегистрированных по месту жительства на территории РФ, обязанность регистрироваться по месту пребывания должна быть отменена, для чего необходимо внести соответствующие изменения как в федеральный закон №5242-1, так и в статью $19.15^{1}$ КоАП РФ, исключив ответственность за отсутствие у граждан России регистрации по месту пребывания.

Объективной стороной указанного правонарушения является умышленное деяние в форме бездействия, заключающегося в нежелании являться в регистрирующий орган с пакетом документов для регистрации по месту пребывания и проживающего таким образом в жилом помещении без регистрации по месту пребывания свыше установленного статьей 5 федерального закона № 5242-1 срока в 90 дней. Обязанность такой регистрации создает особенные неудобства гражданам России, занимающимся садоводством и огородничеством на территории других субъектов Российской Федерации, как граничащих с субъектом, где они зарегистрированы по месту жительства, так и находящихся вдали от этого субъекта. Не совсем ясной представляется ответственность за проживание без регистрации по месту пребывания именно в жилом помещении, поскольку не всякий дачный домик может быть отнесен к жилому помещению. Получается, что лица, проживающие в данном домике, могут не регистрироваться по месту пребыва- 


\section{Административное и муниципальное право 4 (100) • 2016}

ния, поскольку их помещение не является жилым? И в отличие от лиц, проживающих в жилых помещениях, данные лица к ответственности по статье $19.15^{1}$ КоАП РФ привлечены быть не могут. Наиболее часто подобная регистрация создает проблемы для законопослушных граждан, имеющих жилые помещения в разных субъектах Российской Федерации. Не оправдывает законодателя и примечание к статье $19.15^{1}$, где указаны случаи освобождения от административной ответственности за указанное правонарушение. Данные случаи являются разумными обстоятельствами, и привлечение к административной ответственности, например, за проживание без регистрации по месту пребывания в населенном пункте, где гражданин зарегистрирован по месту жительства было бы вообще абсурдным. В то же время для отдельных потенциально опасных для общества граждан, состоящих на различных специальных учетах по месту жительства, как отмечалось выше, такой учет и такая обязанность под угрозой административной ответственности вполне разумны, и в таком случае это уже будет оправдывать цель регистрационного учета как обеспечение защиты прав и законных интересов других граждан. Как вариант, дабы не отрывать законопослушных граждан от дел и забот, органам и должностным лицам Федеральной миграционный службы РФ следует вменить в обязанность вести учет подобных жилых помещений и выезжать к гражданам к месту их длительного (свыше 90 дней) пребывания для регистрации их на месте и снятия с регистрационного учета. Это позволит гражданам не тратить время на сбор всех необходимых документов и на поездку в регистрирующий орган для регистрации по месту пребывания.

В федеральном законе № 5242-1 дано легальное понятие места пребывания и регистрации по месту пребывания. В соответствии со статьей 2 данного закона:

- $\quad$ место пребывания - гостиница, санаторий, дом отдыха, пансионат, кемпинг, туристская база, медицинская организация или другое подобное учреждение, учреждение уголовно-исполнительной системы, исполняющее наказания в виде лишения свободы или принудительных работ, либо не являющееся местом жительства гражданина Российской Федерации жилое помещение, в которых он проживает временно;

- $\quad$ регистрация гражданина Российской Федерации по месту пребывания - постановка гражданина Российской Федерации на регистрационный учет по месту пребывания, то есть фиксация в установленном порядке органом регистрационного учета сведений о месте пребывания гражданина Российской Федерации и о его нахождении в данном месте пребывания [6].
Регистрация, как справедливо отмечает О.Н. Шерстобоев «...представляет собой административно-правовой режим, складывающийся из ряда правовых средств, обеспечивающих стабильность на определенном участке общественных отношений, в том числе связанных с нахождением в стране граждан (российских, иностранных, лиц без гражданства)» $[8$, с.83].

Целью регистрации, по мнению О.Н. Шерстобоева, является административный надзор. «Государство желает отслеживать не только общее количество граждан, находящихся в определенной местности, но и адрес каждого жителя, а также его длительное отсутствие в месте постоянного жительства (на срок более 90 суток). Здесь исполнение обязанности связано с необходимостью стабилизации отечественного правопорядка, а поэтому отдельные ограничения и запреты при отсутствии регистрации вполне допустимы. Тем не менее, демократические государства не должны ставить административный надзор в основу взаимоотношений со своими гражданами. Получается, что в действительности регистрация, вопреки официальным утверждениям, все равно в той или иной степени ограничивает права граждан» [8, с.84-85].

Данное мнение мы полностью поддерживаем и считаем необходимым и важным снизить до минимума административный надзор за законопослушными гражданами, ограничив его только регистрацией по месту жительства.

И правильным, на наш взгляд, в данном случае представляется позиция С.Ю. Миролюбовой, которая говорит о том, что «в настоящее время существует проблема, связанная с тем, что субъекты РФ в рамках защиты прав и свобод жителей, проживающих на территории субъекта, осуществляют правовое регулирование права на свободу передвижения, что влечет ограничение реализации данного права тех граждан, которые не проживают на территории соответствующего субъекта» [5, с.52].

А между тем, на наш взгляд, все законопослушные граждане России вне зависимости от субъекта РФ, где они проживают, имеют право свободно передвигаться и выбирать свободно безо всякой регистрации и иных ограничений место пребывания, не опасаясь отрицательных последствий для себя со стороны правоохранительных органов, привлекающих нарушителей регистрационного режима к административной ответственности за проживание в жилом помещении без регистрации по месту пребывания, пусть и свыше установленного федеральным законом № 5242-1 90-дневного срока.

Рассматривая и анализируя объективную сторону административного правонарушения, предусмотренного статьей $19.15^{1}$ КоАП РФ в части наличия административной ответственности за 
проживание гражданина России в жилом помещении без регистрации по месту пребывания свыше 90-дневного срока, нам неясно, в чем состоит противоправность данного деяния как обязательный признак любого административного правонарушения. Противоправным, на наш взгляд, может считаться лишь то деяние, которое непосредственно направлено против прав и законных интересов личности, общества и государства. В данном конкретном случае мы не видим этой направленности, а потому предлагаем законодателю отменить административную ответственность за проживание гражданина РФ без регистрации по месту пребывания в жилом помещении. Сама идея привлечения к данной ответственности противоречит, по нашему мнению, принципу справедливости и принципу равноправия всех граждан перед законом как основополагающим принципам права, поэтому противоправным данное формальное нарушение закона мы назвать не можем. И позиция законодателя о недавнем введении такой ответственности представляется нам излишней и необоснованной даже с точки зрения ведущих принципов права.

Не совсем обоснованной и разумной представляется нам позиция законодателя ограничить административную ответственность отсутствием регистрации по месту пребывания жилым помещением, поскольку многие граждане, как отмечалось выше, проживают на дачном участке в нежилом помещении, и их, исходя из диспозиции статьи $19.15^{1}$, привлечь к административной ответственности их нельзя. Как нельзя привлечь к данной ответственности цыган и иных лиц, ведущих кочевой образ жизни, а также лиц, у которых нет жилого помещения в собственности и в пользовании, то есть так называемых лиц без определенного места жительства. О необходимости четкого правового регулирования правового статуса бездомных и лиц без определенного места жительства справедливо пишет в своей статье Е.А. Школяренко [9, с.63-64].

Субъектами данного правонарушения могут быть как сами дееспособные граждане, достигшие возраста 16 лет, проживающие без регистрации по месту пребывания в жилом помещении, так и собственники и наниматели жилых помещений, которые привлекают данных граждан как поднанимателей или временных жильцов, а также юридические лица, предоставляющие гражданам жилые помещения для проживания. Наказание предусмотрено одно - административный штраф, размер которого зависит как от субъекта (физическое либо юридическое лицо), так и от места правонарушения (в городах Москве и СанктПетербурге размер штрафа выше, чем в остальных субъектах РФ).
Поскольку данное административное правонарушение имеет формальный состав (наступление вредных последствий не является обязательным условием привлечения к ответственности), то субъективная сторона этого правонарушения характеризуется виной в форме прямого умысла. Правильно, на наш взгляд, отмечается в специальной литературе, что «обязательным признаком административного правонарушения, посягающего на правила паспортно-регистрационной системы, является виновность совершенного деяния. Для признания деяния административным правонарушением необходимо установить, что оно явилось продуктом психической деятельности здравомыслящего лица. Таким образом, не может оцениваться как административное правонарушение противоправное и административно-наказуемое деяние, совершенное помимо воли человека, т.е. лицом, не способным руководить своими действиями, отдавать в них отчет» [3, с.55].

Здесь также может возникнуть проблема у отдельных граждан, связанная с незнанием либо непониманием диспозиции статьи $19.15^{1}$ КоАП РФ. И хотя незнание законов не освобождает от ответственности за содеянное, принцип справедливости требует, на наш взгляд, доведения данной информации должностными лицами регистрирующих органов до сведения всех граждан через средства массовой информации, в том числе местного уровня.

Таким образом, из всего вышесказанного, опираясь на позицию законодателя и точки зрения ученых-юристов, можно сделать вывод, что актуальных проблем административной ответственности за проживание гражданина Российской Федерации без регистрации по месту пребывания в жилом помещении свыше установленного законом срока возникает немало. Решить их можно путем либо исключения административной ответственности для граждан РФ в части проживания без регистрации по месту пребывания в жилом помещении, либо внесения соответствующих изменений и дополнений в статью $19.15^{1}$ КоАП РФ и федеральный закон № 5242-1, обязав регистрироваться по месту пребывания в жилом помещении только отдельные категории потенциально опасных граждан РФ (ранее судимых за совершение умышленных преступлений, состоящих на учетах в наркологических и психоневрологических диспансерах, ведущих антиобщественный образ жизни и т.д.), что будет полностью соответствовать целям регистрационного учета и не будет создавать неудобств для законопослушных граждан Российской Федерации, а также ограничивать их конституционное право на свободу передвижения, выбор места пребывания и жительства. 


\section{Библиография:}

1. Кодекс Российской Федерации об административных правонарушениях от 30.12.2001 N 195-Ф3 (ред. от 04.11.2014). // Российская газета, N 256 от 31.12.2001.

2. Конституция Российской Федерации. Принята на всенародном голосовании 12 декабря 1993 г. (с поправками от 30 декабря 2008 г.) // Российская газета. - 21.01.2009.

3. Костенников М.В., Куракин А.В., Сосновская Ю.Н., Зубач А.В. Паспортно-регистрационная система и административно-правовые средства её обеспечения: Учебное пособие. - М.: Московский университет МВД России, 2005.

4. Костенников М.В., Куракин А.В. Актуальные проблемы науки административного права / Под редакцией Н.А. Овчинникова: Научные школы Всероссийского института повышения квалификации сотрудников МВД России. Т.2. - М.: Маросейка, 2011.

5. Миролюбова С.Ю. Право на свободу передвижения в пределах Российской Федерации: конституционно-правовой аспект. Монография. Издательство Статут, 2013.

6. Федеральный закон от 25 июня 1993 г. №5242-1 (ред. от 31.12.2014 г.) «0 праве граждан Российской Федерации на свободу передвижения, выбор места пребывания и жительства в пределах Российской Федерации». // Российская газета, N 152, 10.08.1993.

7. Федеральный закон от 21.12.2013 г. № 376-Ф3 «0 внесении изменений в отдельные законодательные акты Российской Федерации». // Собрание законодательства РФ, 23.12.2013, N 51, ст. 6696.

8. Шерстобоев О.Н. Регистрация граждан по месту пребывания и месту жительства: проблемы теории и практики. // Российский юридический журнал. 2010. № 2.

9. Школяренко Е.А. Статус бездомных и лиц без определенного места жительства: необходимо четкое правовое регулирование. // Журнал российского права. 2004. №5.

\section{References (transliterated):}

1. Kodeks Rossiiskoi Federatsii ob administrativnykh pravonarusheniyakh ot 30.12.2001 N 195-FZ (red. ot 04.11.2014). // Rossiiskaya gazeta, N 256 ot 31.12.2001.

2. Konstitutsiya Rossiiskoi Federatsii. Prinyata na vsenarodnom golosovanii 12 dekabrya 1993 g. (s popravkami ot 30 dekabrya 2008 g.) // Rossiiskaya gazeta. - 21.01.2009.

3. Kostennikov M.V., Kurakin A.V., Sosnovskaya Yu.N., Zubach A.V. Pasportno-registratsionnaya sistema i administrativnopravovye sredstva ee obespecheniya: Uchebnoe posobie. - M.: Moskovskii universitet MVD Rossii, 2005.

4. Kostennikov M.V., Kurakin A.V. Aktual'nye problemy nauki administrativnogo prava / Pod redaktsiei N.A. Ovchinnikova: Nauchnye shkoly Vserossiiskogo instituta povysheniya kvalifikatsii sotrudnikov MVD Rossii. T.2. - M.: Maroseika, 2011.

5. Mirolyubova S.Yu. Pravo na svobodu peredvizheniya v predelakh Rossiiskoi Federatsii: konstitutsionno-pravovoi aspekt. Monografiya. Izdatel'stvo Statut, 2013.

6. Federal'nyi zakon ot 25 iyunya 1993 g. №5242-1 (red. ot 31.12.2014 g.) «0 prave grazhdan Rossiiskoi Federatsii na svobodu peredvizheniya, vybor mesta prebyvaniya i zhitel'stva v predelakh Rossiiskoi Federatsii». // Rossiiskaya gazeta, N 152, 10.08.1993.

7. Federal'nyi zakon ot 21.12 .2013 g. № 376-FZ «O vnesenii izmenenii v otdel'nye zakonodatel'nye akty Rossiiskoi Federatsii». // Sobranie zakonodatel'stva RF, 23.12.2013, N 51, st. 6696.

8. Sherstoboev O.N. Registratsiya grazhdan po mestu prebyvaniya i mestu zhitel'stva: problemy teorii i praktiki. // Rossiiskii yuridicheskii zhurnal. 2010. № 2 .

9. Shkolyarenko E.A. Status bezdomnykh i lits bez opredelennogo mesta zhitel'stva: neobkhodimo chetkoe pravovoe regulirovanie. // Zhurnal rossiiskogo prava. 2004. №5. 